Бажанов Даниил Владимирович

аспирант кафедры теории и истории государства и права Пермского государственного

национального исследовательского университета

\section{РАЗЛИЧИЕ ЭЛЕМЕНТОВ ПРАВОВОЙ КУЛЬТУРЫ долЖнОСтныХ лиц В ЗАВИСИМОСТИ ОТ ТИПА ОСУЩЕСТВЛЯЕМОЙ ИМИ ДЕЯТЕЛЬНОСТИ}

\section{Аннотация:}

Статья посвящена выявлению отличий в правовой культуре должностных лиц в зависимости от типа юридической деятельности, которую они осуществляют. Дано авторское определение правовой культуры должностного лица, процесс формирования которой состоит из трех последовательных этапов: становление общекультурных установок, появление представлений о правовом и противоправном, вызревание профессиональной правовой культуры. Установлено, что перечень элементов, включаемых в профессиональную правовую культуру должностных лии, зависит от сферы их деятельности. Проведен анализ особенностей правовой культуры должностных лиц законодательной, исполнительной и судебной ветвей власти. Результаты исследования могут быть использованы в ходе организации процедуры оценивания уровня правовой культуры, диагностики правосознания, проведения мероприятий по искоренению правового нигилизма.

\section{Ключевые слова:}

правовая культура, правовой нигилизм, правосознание, должностное лицо, профессиональная правовая культура, судебная власть, законодательная власть, исполнительная власть.
Bazhanov Daniil Vladimirovich

PhD student, Theory and History of State and Law Department, Perm State National Research University

\section{DIFFERENCES IN THE ELEMENTS OF THE LEGAL CULTURE OF OFFICIALS DEPENDING ON THE TYPE OF THEIR ACTIVITY}

Summary:

The paper is devoted to identifying differences in the legal culture of officials depending on the type of legal activity that they carry out. The author's definition of the official's legal culture is given. Its formation consists of three consecutive stages: the generation of cultural attitudes, the emergence of ideas about legal and illegal, and the maturation of professional legal culture. It is established that the list of elements included in the professional legal culture of officials depends on the scope of their activities. The author analyzes the features of the legal culture of officials of the legislative, executive and judicial branches of government. Research results can be used for assessing the level of legal culture, diagnosing legal awareness, and carrying out measures to overcome legal nihilism.

Keywords:

legal culture, legal nihilism, legal awareness, official, professional legal culture, judicial power, legislative power, executive power.

Изучение правовой культуры должностных лиц органов государственной власти и фракторов ее формирования является одним из актуальных направлений теоретико-правовых исследований. Особое внимание ученых и практиков привлекают вопросы, связанные со снижением уровня коррупции - одного из самых распространенных проявлений правовой антикультуры представителей чиновничьего аппарата, а также проблемы искоренения подобных нежелательных элементов из правосознания представителей публичной власти. По данным Министерства внутренних дел России, за январь-фревраль 2020 г. совершено 6323 преступлений коррупционной направленности [1]. В связи распространенностью этого явления появилось такое направление деятельности, как проведение антикоррупционной экспертизы в отношении законопроектов, действующих законов и даже правоприменительных актов [2]. Эфрфективность подобных мер напрямую зависит от того, насколько точное представление об искореняемых элементах правовой культуры имеет их разработчик. Другими словами, до разработки мер по устранению правового нигилизма, негативных последствий низкого уровня правовой культуры следует определиться с понятием этого феномена и его элементами, выявить отличия в правовой культуре должностных лиц в зависимости от типа юридической деятельности, которую они осуществляют.

Попытки сфрормулировать определение правовой культуры многочисленны, но консенсус не достигнут ни в отечественной, ни в зарубежной теории права. «То, что на самом деле подразумевается под правовой культурой, часто остается неясным: правовая культура считается важной, но точного определения нет» [3].

Принято выделять три основных подхода к определению правовой культуры [4]: 
1) фрилософская трактовка заключается в рассмотрении данного феномена как явления, имеющего свои закономерности развития и не связанного с обществом, т.е. правовая культура понимается как метасфера по отношению к человеку и социуму;

2) антропологическое понимание правовой культуры сводится к ее отождествлению с неким рукотворным благом [5], системой артефактов, верований, обычаев и знаний [6];

3) ценностный подход поддерживается и развивается многими представителями юридического сообщества, т.к. наиболее полно отражает сущность правовой культуры и ее предназначение. Л.М. Фридман дает следующее определение: «это идеи, установки, ценности и мнения о праве, правовой системе» [7, с. 53]. Д. Нелькен полагает, что правовая культура - это один из способов описания относительно устойчивых образцов юридически ориентированного социального поведения и установок [8].

И.А. Демидова выделяет также информационно-семиотический подход, в контексте которого правовая культура определяется как «совокупность результатов правовой деятельности, выступающих в роли предметов-знаков, которые несут в себе правовую информацию» [9]. Предметы-знаки, по мнению автора, выражаются в знании, ценностях, регулятивах. Следовательно, этот способ понимания правовой культуры может быть отнесен к ценностному подходу.

Одним из распространенных приемов определения понятия является перечисление его элементов, что логически ошибочно, т.к. операция дефинирования подменяется анализом. Однако разложение понятия на элементы важно для достижения практических целей. Так, М. Хекке и М. Уоррингтон выделяют шесть элементов правовой культуры: юридическая терминология, правовые источники, правовые методы, теория аргументации, легитимация права, общая идеология [10]. С.А. Комаров пишет, что в правовую культуру входит правосознание, правовая деятельность и уровень развития юридических актов [11, с. 331].

Большинство исследователей, понимание правовой культуры которых различается, тем не менее сходится во мнении относительно ее предназначения. Р. Коттеррелл сравнивает ее с «линзой, через которую должны восприниматься все аспекты права, или вратами понимания, через которые должен пройти каждый компаративист, чтобы иметь подлинный доступ к смыслу иностранного права» [12]. 3.А. Горюшкин полагал, что ядром права выступает «народное умствование» [13].

На наш взгляд, целям определения места и назначения правовой культуры, а также выявления эффрективных рычагов ее корректировки наиболее полно отвечает именно ценностный подход. Правовую культуру должностных лиц мы будем понимать как взаимосвязанную совокупность ценностных ориентиров должностного лица, определяющую его деятельностные проявления в правовой сфере, связанные с реализацией возложенных полномочий.

Первенство в диффреренциации правовой культуры по субъекту-носителю приписывается Л.М. Фридману, который предложил выделять внутреннюю и внешнюю правовую культуру: внутренняя характеризует отношение к праву судей и адвокатов, внешняя - отношение широких слоев населения [14]. Для правовой культуры должностных лиц характерен высокий уровень политизированности, т.к. «она отражает и определяет то, как индивиды видят себя не по отношению друг к другу, а по отношению к государству» [15]. По нашему мнению, отличия в элементном составе правовой культуры имеются не только между лицами, которые занимаются каким-либо видом юридической деятельности, и всеми иными лицами, но и между должностными лицами в зависимости от типа юридической деятельности, которую они осуществляют.

Процесс формирования правовой культуры должностного лица состоит из трех последовательных этапов: становление общекультурных установок, которое является базисом для наслоения представлений о правовом и противоправном, затем на этой почве вызревают элементы культуры, связанные именно с тем видом юридической деятельности, которое ведет должностное лицо. Состав третьего слоя культуры должностных лиц, причастных к отправлению правосудия, будет отличаться от элементов правовой культуры лиц, включенных в иные ветви власти.

Безусловно, есть аспекты профессиональной правовой культуры должностных лиц, которые должны быть присущи всему чиновничьему аппарату; их подробный анализ, а также способы определения уровня правовой культуры даны С.Б. Поляковым [16, с. 14, 15, 35, 299, 301, 306]. Нам бы хотелось остановиться именно на отличительных особенностях правовой культуры должностных лиц, исходя из той профессиональной деятельности, которую они осуществляют.

На наш взгляд, профессиональная правовая культура должностных лиц судебной ветви власти характеризуется рядом особенностей.

1. Подверженность действию культурных установок судейского корпуса, связанность правовыми позициями высших судов, использование актов официального толкования и актов Верховного суда (ВС) и Конституционного суда (КС) РФ по конкретным делам в качестве источника права. Представление о стандарте отправления правосудия у судей формируется на основе тех разъяснений, которые транслируют ВС и КС РФ, даже если данное ими толкование расходится с буквой 
закона, а также с правовыми позициями, которые выработаны ВС РФ при рассмотрении конкретных дел. Например, в Определении ВС РФ от 10 декабря 2019 г. по делу № 44-КГ 19-28 судебной коллегией сделан вывод о том, что п. 4 ст. 1109 ГК РФ применяется только при дарении или с благотворительной целью, в то время как п. 4 ст. 1109 ГК РФ указание на дарение не содержит, а говорит о невозможности возврата неосновательного обогащения при несуществующем обязательстве. Такие расхождения позиций судов с законодательными формулировками приводят к тому, что в правовой культуре судей появляется представление о превалировании актов толкования высших судов над нормой права, принятой законодательной ветвью власти. Схожая ситуация наблюдается и в зарубежной практике. «Бюрократическая судебная система использует интерпретацию, чтобы соответствовать требованиям своей иерархии или навязывать свое собственное толкование норм» [17, с. 359]. Следует отметить, что эта особенность не характерна для должностных лиц, участвующих в правотворческой деятельности законодательных (представительных) органов.

2. Источником создания специальных культурных установок служат также многочисленные решения квалификационной коллегии судей, которая дает оценку действиям/бездействиям судьи, В том числе с позиции проверки наличия у конкретного лица требуемого уровня правовой культуры. Несмотря на то, что акты квалификационной коллегии являются актами индивидуального применения, их содержание и выводы включаются в культуру членов судейского сообщества.

3. Отрешенность судей от участия в законотворческой деятельности приводит к доминированию в их сознании позитивистской трактовки права над иными типами правопонимания, что в крайней своей форме выражается в принятии решения без учета духа закона или в отсутствии в решении звеньев правовой квалификации, самого толкования норм, когда суд ограничивается лишь механическим цитированием закона в тексте решения и сразу переходит к резолютивной части. Такое положение дел часто критикуется научным сообществом [18]. В зарубежной литературе также говорится о важности развернутого и внятного толкования применяемой судом нормы: «часто бывает, что, оценивая фракты и рассматривая их в свете правил, судья должен иллюстрировать свое мнение..., ибо иллюзорная ясность заповеди вызывает сомнение в связи с ее применением» [19, с. 43].

4. Профессиональная правовая культура судей опирается на полученное ими специальное юридическое образование, что отличает их, например, от должностных лиц исполнительной власти, которые могут не иметь юридического образования, а иметь иное высшее образование, включая государственное и муниципальное управление, экономические и прочие специальности. Хотя в науке утверждается, что правовая культура относится не только к «инсайдерской культуре» тех, кто получил юридическое образование, а проистекает из взаимосвязи политических, социальных и правовых традиций и институтов [20], практики и неформального опыта правовой культуры, отсутствие правового знания не может не влиять на уровень правовой культуры и тем более на показатели профессиональной правовой культуры. В связи с этим часто цитируются слова А. Токвиля, адвоката и политика, автора труда «Демократия в Америке»: «Дух адвоката, рожденный в школах и залах судебных заседаний, мало-помалу распространяется за их пределы, он, так сказать, проникает во все общество, опускается до самых низов, и народ в целом в конце концов становится частью привычек и вкусов магистрата. Таким образом, компетентность юристов обобществляется» [21, с. 138]. На наш взгляд, А. Токвиль в данном случае говорит о том, что три ранее названных слоя культуры не являются замкнутыми и статичными, то, что сегодня является элементом только профессиональной правовой культуры, завтра может стать частью правовой культуры непрофессионального сообщества. Тем не менее наличие системного понимания правовых процессов, характерного именно для профессиональной правовой культуры, более вероятно зафиксировать у тех лиц, кто имеет специальное юридическое образование или специальные знания в данной области.

5. Система норм, ориентированная на повышенную защиту судей от посягательств различного рода, сама по себе является инструментом, законодательно закрепляющим требование об уважительном отношении к суду, и должна оцениваться положительно. Но у судей с низким уровнем правовой культуры эта система норм вызывает появление антиправовых элементов на профессиональном уровне. Известны многочисленные случаи некорректного или унижающего поведения судьи в адрес лиц, участвующих в деле. Высока латентность таких ситуаций, т.к. стороны, опасаясь ухудшения обстановки на судебном разбирательстве, предпочитают умолчать о непрофессионализме судьи. Предоставление правового иммунитета судьям многими учеными оценивается как гарантия их безответственности [22]. Таким образом, предоставленные судьям привилегии и преимущества являются почвой для перехода антиправовых элементов в их культуре со второго уровня на третий, профессиональный, уровень.

К особенностям профессиональной правовой культуры должностных лиц, осуществляющих функции, характерные для исполнительной ветви власти, следует отнести: 
1) использование в качестве источника права разъяснений вышестоящих должностных лиц, органов государственной власти, которые не являются нормативно-правовыми актами, но де-фракто содержат положения, распространяемые на неопределенный круг лиц, рассчитанные на неоднократное применение и пр. В силу иерархичности государственных структур эти разъяснения становятся обязательными для применения должностными лицами. К таким актам можно отнести, например, письма Федеральной налоговой службы и Министерства фринансов РФ [23];

2) отсутствие специальных правовых знаний у некоторой части представителей должностных лиц в связи с получением ими иного профильного образования. Модель «чиновникаюриста» заменяется «государственным менеджером». Это выражается в том, что высшие должностные лица зачастую не имеют юридического образования, а наличие лишь правовых знаний больше не считается достаточным, чтобы быть государственным служащим [24].

Особенность правовой культуры должностных лиц, осуществляющих законотворческую деятельность, заключается в обязательном наличии элемента правового предвидения. Законодательная деятельность является отправной точкой формирования системы российского права. Г. Кельзен писал, что «производство правовых норм является основным источником правил, обрамляющих социальную игру» [25, с. 453]. Это означает, что лица, фрормулирующие правила поведения для неограниченного круга лиц, должны иметь максимально высокий уровень правовой культуры, позволяющий создать такое регулирование, которое снизит вероятность преобладания правоприменительного усмотрения над духом и буквой закона, возникновения необходимости принятия разъяснений по правоприменению, восполняющих нормативное регулирование вместо законодателя.

В «Докладе Брейбанта», который часто упоминается в зарубежных трудах, зафиксировано, что государственные служащие все меньше и меньше контролируют как разработку, так и применение правовых норм: качество законопроектов и декретов ухудшается; их применение сопровождается инфляцией циркуляров; множатся источники судебных разбирательств [26]. Это означает, что в правовую культуру должностных лиц законодательной ветви власти должен включаться такой элемент, как правовое предвидение реализации созданной нормы права. Также требуется наличие высокого уровня юридической техники написания нормативных актов. Излишняя сложность и запутанность нормативного изложения являются изъянами правовой культуры, поскольку препятствует однозначному уяснению вводимого правила. В Российской Федерации отсутствует механизм признания нормы недействующей из-за ее сложности, но это возможно в некоторых других странах. Например, Конституционный совет Франции отменял законодательные положения, которые «имели чрезмерную сложность» [27].

Завершая наше исследоание, отметим, что под правовой культурой должностного лица в рамках аксиологического подхода следует понимать взаимосвязанную совокупность ценностных ориентиров должностного лица, определяющую его деятельностные проявления в правовой сорере, связанные с реализацией возложенных полномочий. Перечень элементов, включаемых в правовую культуру должностных лиц, должен определяться с учетом сферы их профессиональной деятельности. В этом случае процедуры оценивания уровня правовой культуры и диагностики правосознания будут более результативны и эффективны.

\section{Ссылки:}

1. Краткая характеристика состояния преступности в Российской Федерации за январь-февраль 2020 года [Электронный ресурс] // Министерство внутренних дел Российской Федерации. URL: https://мвд.pdp/reports/item/19897618/ (дата обращения: 20.04.2020)

2. Антикоррупционная экспертиза нормативно-правовых актов и их проектов / сост. Е.Р. Россинская. М., 2010. 96 с.

3. Michaels R. Legal Culture (Forthcoming in Oxford Handbook of European Private Law, Oxford University Press) // Duke Law Schollarship Repository. URL: https://scholarship.law.duke.edu/cgi/viewcontent.cgi?article=3012\&context=faculty_scholarship (дата обращения: 02.06.2020).

4. Кертман Л.Е. К методологии изучения культуры и критики ее идеалистических концепций // Новая и новейшая история. 1973. № 3. С. 32-47.

5. Merry S. What is Legal Culture? An Anthropological Perspective // Journal of Comparative Law. 2012. № 5 (2). P. $40-58$.

6. Демидова И.А. Определение правовой культуры в теории права // Вестник Санкт-Петербургского университета МВД России. 2017. № 2 (74). С. 28-33.

7. Friedman L.M. Some Thoughts on Comparative Legal Culture // Comparative and Private International Law: Essays in Honor of John Henry Merryman on his Seventieth Birthday / ed. by D. Clark. Berlin, 1990. P. 49-57.

8. Nelken D. Using the Concept of Legal Culture // Legal Theory and the Social Sciences. L., 2017. P. 279-303. https://doi.org/10.4324/9781315091891-11.

9. Демидова И.А. Указ. соч. С. 31

10. Hoecke M., Warrington M. Legal Cultures, Legal Paradigms and Legal Doctrine: Towards a New Model for Comparative Law // International and Comparative Law Quarterly. 1998. № 47 (3). P. 495-536.

11. Комаров С.А. Общая теория государства и права. М., 1998. 416 с.

12. Cotterrell R. Comparative Law and Legal Culture // The Oxford Handbook of Comparative Law / ed. by M. Reimann, R. Zimmermann. Oxford, 2019. P. 709-733. https://doi.org/10.1093/oxfordhb/9780198810230.013.22.

13. Томсинов В.А. Русский законоискусник Захар Аникеевич Горюшкин // Закон. 2009. № 6. С. 241-249. 
14. Michaels R. Op. cit.

15. Brants C. Legal Culture and Legal Transplants // Electronic Journal of Comparative Law. 2010. Vol. 14.3. URL: https://www.ejcl.org/143/art143-5.pdf (дата обращения: 20.04.2020).

16. Поляков С.Б. Диагностика правосознания правоприменителей. Пермь, 2017. 356 с.

17. Spire A. Étrangers à la Carte? L'administration de l'Immigration en France (1945-1975). Paris, 2005. 402 p.

18. Поляков С.Б., Колосова Ю.Д. Первый опыт программирования судебного решения //Актуальные проблемы экономики и права. 2017. Т. 11, № 2 (42). С. 131-144. https://doi.org/10.21202/1993-047x.11.2017.2.131-144.

19. Plazas Vega M. Del Realismo al Trialismo Jurídico. Bogotá, 1998. 186 p.

20. Brants C. Op. cit.

21. Цит. по: Oskian G. Tocqueville and the Legal Culture of Jacksonian America // Journal of the Early Republic. 2019. Vol. 39, № 1. P. 135-143. https://doi.org/10.1353/jer.2019.0011.

22. Репьев А.Г. Правовая культура - неотъемлемый элемент права на иммунитет должностного лица государства // Правовая культура. 2011. № 2 (11). С. 102-105.

23. Дементьев И.В. Постановление Конституционного Суда РФ от 31 марта 2015 г. № 6-П и проблемы толкования налогового законодательства // Налоговое право в решениях Конституционного Суда Российской Федерации 2015 года: материалы XIII Международной научно-практической конференции (Москва, 15-16 апреля 2016 г.). М., 2017. С. $34-42$.

24. Lascoumes P. Pour une Formation à la “Gouvernementalité" // Revue Française d’Administration Publique. 1989. № 51. P. 113-124.

25. Kelsen H. Théorie Pure du Droit. Paris, 1962. 496 p.

26. Chevallier J. La Place de l'Administration Dans la Production des Normes // Droit et Société. 2011. Vol. 79, № 3. P. $623-636$. https://doi.org/10.3917/drs.079.0623.

27. Ibid.

Редактор, переводчик: Арсентьева Ирина Ильинична 